\title{
Utilização de óleos vegetais em dietas para juvenis de piava (Leporinus obtusidens)
}

\author{
Utilization of vegetables oils in diets for piava juveniles (Leporinus obtusidens)
}

\section{Taida Juliana Adorian*, Patrícia Inês Mombach, Dirleise Pianesso, Juliano Uczay, Junior Decarlli e Rafael Lazzari}

Recebido em 24/09/2016 / Aceito em 29/12/2016

\section{RESUMO}

Objetivou-se avaliar a resposta de piavas (Leporinus obtusidens) após a utilização de óleos vegetais nas dietas, sobre o desempenho, deposição nutricional e atividade de enzimas digestivas. Durante 35 dias foram testadas cinco dietas, com a inclusão de $3 \%$ dos óleos de milho, soja, canola, linhaça e um tratamento controle sem inclusão de óleo. Peixes com peso inicial médio de 1,78 $\pm 0,07 \mathrm{~g}$ foram distribuídos ao acaso em um sistema de recirculação de água composto por 15 tanques, com parâmetros de qualidade de água adequados durante todo período experimental. Ao final do experimento realizou-se biometria para coleta de dados. O delineamento experimental foi inteiramente casualizado, com cinco tratamentos e três repetições, os dados obtidos foram submetidos a teste de normalidade e análise de variância. As médias obtidas, quando significativas, foram comparadas pelo teste de Tukey $(\mathrm{p}<0,05)$. Os peixes alimentados com dietas contendo óleo de canola apresentaram maior peso e comprimento total e deposição de proteína, quando comparados ao tratamento controle. Maior atividade de quimotripsina foi observada nos peixes alimentados com a dieta contendo óleo de soja e menor com óleo de linhaça. Conclui-se que o uso de óleos na dieta é indispensável para melhor desempenho dos peixes, sendo o óleo de canola o mais indicado por otimizar a deposição de proteína corporal pelos animais.

PALAVRAS-CHAVE: óleo de canola, fontes lipídicas, peixe, enzimas digestivas, desempenho.

\footnotetext{
ABSTRACT

This study aimed to evaluate the response of piava (Leporinus obtusidens) after the use of vegetable oils

Universidade Federal de Santa Maria, Santa Maria, RS, Brasil.

*Autor para correspondência <taidajuliana@yahoo.com.br>
}

in the diet, under performance, nutrient deposition and activity of digestive enzymes. Over 35 days five treatments were tested, with the inclusion of $3 \%$ of corn oil, soy, canola, linseed, and a control treatment without the inclusion of oil. Fish with an average initial weight of $1.78 \pm 0.07 \mathrm{~g}$ were randomly assigned in a water recirculation system consisting of 15 tanks, with suitable water quality parameters throughout the trial period. At the end of biometrics experiment data was collected. The experimental design was completely randomized, with five treatments and three replicates; the data was submitted to normality test and analysis of variance. The averages, when significant, were compared by Tukey test $(p<0.05)$. Fish fed diets containing canola oil showed higher weight and length and protein deposition when compared to the control treatment. Higher chymotrypsin activity was observed in the fish fed the diet containing soya oil and lower with linseed oil. It is concluded that the use of oils in the diet is essential for best performance of the fish, and canola oil as indicated by optimizing the deposition of body protein for animals.

KEYWORDS: canola oil, lipid sources, fish, digestive enzymes, growth performance.

\section{INTRODUÇÃO}

Atualmente a aquicultura é a atividade responsável pela produção da proteína de origem animal mais consumida no mundo. Somente em 2011, foram produzidas cerca de 170 milhões de toneladas de pescado, sendo 130,8 milhões de toneladas destinadas ao consumo humano (MPA 2014). No Brasil a atividade ocupa a $17^{\mathrm{a}}$ posição no ranking mundial na produção de pescados em cativeiro (MPA 2014). Para que possa continuar crescendo de forma competitiva, a aquicultura brasileira precisa investir 
em pesquisar visando a expansão da produção de espécies nativas com potencial de cultivo.

$\mathrm{Na}$ região Sul do país, uma espécie que vem chamando a atenção de produtores e consumidores é a piava (Leporinus obtusidens), espécie de hábito alimentar onívoro que se alimenta principalmente de sementes, insetos aquáticos, crustáceos e moluscos, tendo ocorrência nas bacias do rio Uruguai e São Francisco. É um peixe migrador, da família Anastomidae, com peso corporal que pode chegar a 7,5 $\mathrm{kg}$ (TAITSON et al. 2008). A qual tem boa aceitação pelo mercado consumidor por possuir excelente qualidade de carne, além de ser bastante apreciada por pescadores esportivos. Apesar destas características, pouco se conhece a respeito da nutrição da piava.

Os lipídios desempenham funções importantes para peixes, devendo ser melhor estudados, principalmente no caso de espécies como a piava. Além de ser uma das principais fontes energéticas para os animais, os lipídios desempenham papel em processos fisiológicos e exercem influência sobre a presença de ácidos graxos corporais (PEREIRA et al. 2011). Além disso, um balanço energético e proteico adequado das dietas otimiza o desempenho dos animais, resultando em bons índices produtivos e retenção de proteína corporal (SIGNOR et al. 2010).

Assim, fica clara a importância da fração lipídica em dietas para peixes, a qual também é responsável pelo fornecimento de maneira eficiente de ácidos graxos essenciais (AGE) aos animais. A utilização de óleos como fonte lipídica possibilita a diminuição na quantidade de proteína necessária na formulação de rações, assim como seu custo, fornecendo aporte de AGE necessários para o bom desenvolvimento dos peixes (MARTINO et al. 2002). Há também preocupações do ponto de vista econômico e ambiental, pois a sustentabilidade da piscicultura a longo prazo é dependente da descoberta de ingredientes alternativos ao óleo de peixe, fonte oriunda do extrativismo.

Diferentes fontes lipídicas têm sido estudadas para peixes nativos brasileiros, observando-se que o tipo de óleo usado nas dietas pode influenciar parâmetros de crescimento e de composição corporal dos animais. Os óleos de soja, girassol, canola, milho, linhaça e arroz estão entre as fontes de origem vegetal mais estudadas em dietas para peixes (MARTINO et al. 2002, MELO et al. 2002, VARGAS et al. 2007, LOSEKANN et al. 2008). Entretanto, não são encontrados na literatura estudos avaliando fontes energéticas para a piava, ou quaisquer outros temas relacionados a fração energética das dietas para esta espécie.

Em busca de informações sobre a viabilidade técnica de utilização de óleos vegetais em dietas para piavas, o objetivo desse trabalho foi avaliar o desempenho, deposição nutricional e atividade de enzimas digestivas de juvenis de piava alimentadas com diferentes fontes lipídicas na dieta.

\section{MATERIAL E MÉTODOS}

O estudo foi conduzido durante 35 dias nas instalações do Laboratório de Piscicultura da Universidade Federal de Santa Maria, Campus de Palmeira das Missões, RS (altitude de $639 \mathrm{~m}$, longitude oeste $53^{\circ} 18^{\prime} 49^{\prime}$ ", latitude sul). Utilizou-se um sistema de recirculação de água composto por 15 tanques de polipropileno revestidos com fibra de vidro $(250 \mathrm{~L})$, com entrada e saída de água individuais, reservatório de água (2000 L), biofiltro com pedra britada para filtragem biológica da água, termostatos para controle de temperatura e aeradores para manutenção do nível de oxigênio.

Foram utilizados 375 juvenis de piava com peso médio inicial de $1,78 \pm 0,07 \mathrm{~g}$, distribuídos ao acaso nas 15 unidades experimentais, sendo 25 peixes por tanque. Para início do período do ensaio biológico, esses animais foram submetidos a uma biometria inicial para pesagem e medição dos animais, de modo a obter-se o peso médio inicial $(\mathrm{g})$ e comprimento total (cm) dos peixes. Na mesma oportunidade coletouse uma amostra inicial dos peixes para posterior determinação da composição corporal segundo a AOAC (1995).

Para a fabricação das dietas, os ingredientes foram pesados individualmente e misturados através de amassadeira elétrica até completa homogeneização. Posteriormente adicionou-se água e os diferentes óleos à mistura e foi realizada peletização, sendo as dietas levadas à estufa de circulação de ar forçado por 24 horas, a uma temperatura de $55^{\circ} \mathrm{C}$ para secagem. Depois de secas, foram moídas e peneiradas para a obtenção de grânulos adequados ao tamanho dos peixes. Foram testadas cinco dietas, variando as fontes de lipídios: óleo de linhaça (OL), soja (OS), canola (OC), milho (OM), incluídas na quantidade de $3 \%$ e um tratamento controle (TC) sem inclusão de óleo (Tabela 1). 
Tabela 1 - Composição das dietas experimentais (\%).

Table 1 - Composition of experimental diets (\%).

\begin{tabular}{lccccc}
\hline & \multicolumn{5}{c}{ Fontes lipídicas } \\
\cline { 2 - 6 } Ingredientes & Linhaça & Soja & Canola & Milho & Controle \\
Farelo de soja & 47 & 47 & 47 & 47 & 46 \\
Farelo de linhaça & 3 & 3 & 3 & 3 & 6 \\
Glúten de trigo & 5 & 5 & 5 & 5 & 5 \\
Milho moído & 10 & 10 & 10 & 10 & 11 \\
Farelo de arroz desengordurado & 29 & 29 & 29 & 29 & 29 \\
Óleo de linhaça & 3 & - & - & - & - \\
Óleo de soja & - & 3 & - & - & - \\
Óleo de canola & - & - & 3 & - & - \\
Óleo de milho & - & - & - & 3 & - \\
Vitaminas e minerais* & 1 & 1 & 1 & 1 & 1 \\
Fosfato bicálcico & 1 & 1 & 1 & 1 & 1 \\
Sal & 1 & 1 & 1 & 1 & 1 \\
\hline & & & Composição & & \\
& & & & & \\
\hline Umidade & 5,95 & 11,02 & 8,25 & 11,25 & 11,46 \\
Proténa bruta & 34,64 & 34,55 & 35,19 & 34,45 & 34,99 \\
Lipídios & 6,49 & 6,07 & 6,46 & 5,82 & 4,21 \\
Fibra bruta & 8,50 & 8,50 & 8,50 & 8,50 & 10,05 \\
Energia bruta & 3967 & 3969 & 3965 & 3963 & 3802 \\
Cinzas & 8,85 & 8,56 & 8,44 & 8,38 & 8,47 \\
\hline
\end{tabular}

${ }^{1}$ Valores de umidade, proteína, lipídios e cinzas foram analisados segundo a AOAC (1995) e valores de fibra bruta e energia bruta calculados segundo as Tabelas Brasileiras para aves e suínos: composição de alimentos e exigências nutricionais (ROSTAGNO 2011).

"Mistura vitamínica e mineral (kg/produto): ácido fólico: $250 \mathrm{mg}$; ácido pantotênico: $5.000 \mathrm{mg}$; antioxidante: 0,60 g; biotina: $125 \mathrm{mg}$; cobalto: $25 \mathrm{mg}$; cobre: $2.000 \mathrm{mg}$; ferro: $820 \mathrm{mg}$; iodo: $100 \mathrm{mg}$; manganês $3.750 \mathrm{mg}$; niancina $5.000 \mathrm{mg}$; selênio: $75 \mathrm{mg}$; vitamina A: 1.000 .000 UI vitamina B1: 1.250 $\mathrm{mg}$; vitamina B12: $3.750 \mathrm{mcg}$; vitamina B2: $2500 \mathrm{mg}$; vitamina B6: $2.485 \mathrm{mg}$; vitamina C: $28.000 \mathrm{mg}$; vitamina D3: 500.000 U.I; vitamina E: 20.000 UI; vitamina K: $500 \mathrm{mg}$; zinco: $17.500 \mathrm{mg}$. TC: sem inclusão de óleo vegetal; OS: óleo de soja; OM: óleo de milho; OC: óleo de canola; OL: óleo de linhaça.

Os peixes foram alimentados três vezes ao dia, nos horários das 9:00, as 12:00 e 16:30 h, na proporção de $5 \%$ do peso vivo por dia.

Para manutenção da qualidade da água de cultivo, antes da primeira alimentação diária realizouse sifonagem para retirada de resíduos e fezes dos tanques. Diariamente foram analisados os parâmetros de água, os quais foram mantidos em: $\mathrm{pH}$ 7,5; temperatura pela manhã $23,02 \pm 2,15^{\circ} \mathrm{C}$; temperatura pela tarde $24,35 \pm 2,05{ }^{\circ} \mathrm{C}$; oxigênio $4,06 \pm 0,24 \mathrm{ppm}$; amônia $1,19 \pm 0,73 \mathrm{ppm}$; nitrito $0,02 \pm 0,01 \mathrm{ppm}$; alcalinidade $38,8 \pm 3,89 \mathrm{CaCO}_{3} / \mathrm{L}$; dureza $56,8 \pm 5,40$ $\mathrm{CaCO}_{3} / \mathrm{L}$. Não foi observada mortalidade de peixes durante o ensaio, podendo-se considerar os valores adequados para a criação de peixes.

Semanalmente foram realizadas pesagens de biomassa, através da pesagem coletiva dos peixes de cada unidade experimental, para posterior ajuste da oferta de ração. Ao final do ensaio biológico os animais passaram por jejum de 12 horas e foram sedados com o anestésico óleo de cravo diluído em água (concentração de $0,02 \%$ ), para realização de biometria e coleta de dados de peso e comprimento. A partir das medidas biométricas foram estimados os seguintes parâmetros: peso médio (g); comprimento total $(\mathrm{cm})$; taxa de crescimento específico, TCE = [100 (In Peso final - In Peso inicial)] / tempo (dias) e fator de condição $(\mathrm{FC}), \mathrm{FC}=($ Peso final - Peso inicial)/Comprimento Total.

Foram coletadas amostras de sangue de três peixes por unidade experimental através de punção no vaso caudal, para determinação da glicose plasmática a qual teve leitura realizada imediatamente após a coleta, através de aparelho medidor portátil (Accu- 
check Active $\left.^{\circledR}\right)$, os quais não foram submetidos a sedação. Posterior a coleta de sangue, estes foram abatidos por hipotermia, para coleta de intestino e posterior determinação da atividade das enzimas tripsina e quimotripsina, conforme metodologia descrita por HUMMEL (1959) e lipase de acordo com GAWLICKA et al. (2000). Para determinação da composição corporal dos peixes, uma amostra de dez peixes por tratamento foi coletada.

A composição das dietas e a composição corporal dos peixes foram realizadas conforme a AOAC (1995). A umidade foi determinada pela perda de peso da amostra após 4 horas a $60{ }^{\circ} \mathrm{C}$ em estufa com circulação forçada de ar, seguida de 8 horas a $105^{\circ} \mathrm{C}$; o conteúdo de cinzas foi determinado a $550{ }^{\circ} \mathrm{C}$ e proteína bruta $(\mathrm{N} \times 6,25)$ pelo método de micro Kjeldahl. Os teores de lipídios foram quantificados seguindo o método de BLIGH \& DYER (1959). A partir da composição corporal dos peixes, calculou-se os índices de deposição nutricional, sendo eles:

-Deposição de proteína corporal $(\mathrm{g})$ :

$\mathrm{DPC}=[\mathrm{Pf} *(\% \mathrm{PBCf} / 100)]-[\mathrm{Pi} * \% \mathrm{PBCi} / 100)] ;$

-Deposição de gordura corporal $(\mathrm{g})$ :

$\mathrm{DGC}=[\mathrm{Pf} *(\% \mathrm{GCf} / 100)]-[\mathrm{Pi} *(\% \mathrm{GCi} / 100)]$.

Onde:

$\mathrm{PBCi}=$ proteína corporal inicial; $\mathrm{PBCf}=$ proteína corporal final; GCi: gordura corporal inicial; GCf: gordura corporal final.

O delineamento experimental foi o inteiramente casualizado, com cinco tratamentos e três repetições (15 tanques). Os dados obtidos foram submetidos a teste de normalidade (Shapiro-Wilk) e detecção de observações anormais (outliers), onde foram excluídas as maiores ou menores que a média ( $2 *$ desvio padrão). Após aplicou-se análise de variância paramétrica $(\mathrm{p}<0,05)$. As médias obtidas, quando significativas, foram comparadas pelo teste de Tukey.

\section{RESULTADOS E DISCUSSÃO}

Os resultados de desempenho e deposição de nutrientes obtidos neste estudo são apresentados na Tabela 2. Pode-se observar que o ganho de peso e o comprimento final das piavas não diferiam entre os tratamentos com adição de óleos de soja, milho, linhaça e canola, porém os animais alimentados com dieta contendo óleo de canola obtiveram ganhos superiores $(4,53 \mathrm{~g})$ aos submetidos a dieta sem adição de óleo (3,68 g). Corroborando com os resultados obtidos, estudos mostram que diferentes fontes de lipídios não interferem no crescimento dos peixes. Para juvenis de linguado senegalês (Solea senegalensis), não foram observados quaisquer efeitos negativos sobre o desempenho ou a eficiência alimentar ao substituir totalmente o óleo de peixe por óleo de linhaça (BENÍTEZ-DORTA et al. 2013) ou por uma mistura de óleo de óleos vegetais contendo óleo de linhaça, de soja e de colza (BORGES et al. 2014). Da mesma forma, para a tilápia do Nilo (Oreochromis

Tabela 2 - Parâmetros de desempenho e deposição de nutrientes de juvenis de piava alimentadas com dietas contendo óleos vegetais.

Table 2 - Performance parameters and deposition of piava juveniles fed diets containing vegetable oil nutrients.

\begin{tabular}{|c|c|c|c|c|c|c|}
\hline \multicolumn{7}{|c|}{ Fontes de lipídios } \\
\hline Variáveis & Linhaça & Soja & Canola & Milho & Controle & $\mathrm{P}$ \\
\hline PI (g) & $1,86 \pm 0,09$ & $1,80 \pm 0,16$ & $1,78 \pm 0,04$ & $1,72 \pm 0,17$ & $1,71 \pm 0,13$ & NS \\
\hline GP (g) & $4,42 \pm 0,14^{a b}$ & $4,08 \pm 0,29 a b$ & $4,53 \pm 0,45^{\mathrm{a}}$ & $4,10 \pm 0,22 \mathrm{ab}$ & $3,68 \pm 0,29^{b}$ & $*$ \\
\hline $\mathrm{CT}(\mathrm{cm})$ & $6,93 \pm 0,10^{a b}$ & $6,91 \pm 0,17^{\mathrm{ab}}$ & $6,98 \pm 0,09^{\mathrm{a}}$ & $6,78 \pm 0,05^{a b}$ & $6,58 \pm 0,22^{b}$ & $*$ \\
\hline $\mathrm{FC}$ & $1,33 \pm 0,09$ & $1,23 \pm 0,07$ & $1,32 \pm 0,08$ & $1,31 \pm 0,04$ & $1,28 \pm 0,05$ & NS \\
\hline TCE $(\% /$ dia $)$ & $2,47 \pm 0,23$ & $2,32 \pm 0,19$ & $2,65 \pm 0,27$ & $2,48 \pm 0,15$ & $2,17 \pm 0,08$ & NS \\
\hline DPC (g/dia) & $0,38 \pm 0,02^{a b}$ & $0,32 \pm 0,02^{b c}$ & $0,44 \pm 0,06^{\mathrm{a}}$ & $0,41 \pm 0,01^{a b}$ & $0,27 \pm 0,02^{\mathrm{c}}$ & $* *$ \\
\hline DGC (g/dia) & $0,25 \pm 0,01^{\mathrm{a}}$ & $0,21 \pm 0,01^{\mathrm{a}}$ & $0,24 \pm 0,02^{\mathrm{a}}$ & $0,22 \pm 0,01^{\mathrm{a}}$ & $0,15 \pm 0,01^{b}$ & $* *$ \\
\hline
\end{tabular}

PI: peso inicial; GP: ganho de peso; CT: comprimento total; FC: fator de condição; TCE: taxa de crescimento específico; DPC: deposição de proteína corporal; DGC: deposição de gordura corporal. Valores apresentados como médias \pm desvio padrão. Valores acompanhados de letras diferentes, na mesma linha, são estatisticamente diferentes de acordo com o teste de Tukey $(* \mathrm{p}<0,05 ; *$; $<0,01)$. 
sp.) a utilização de óleo de palma, linhaça ou soja não proporcionou diferenças significativas nos parâmetros de crescimento dos peixes (NG et al. 2013).

Além de desempenho superior a dieta, o óleo de canola também proporcionou uma maior deposição de nutrientes corporais às piavas (Tabela 2 ). A deposição de proteína corporal foi significativamente superior a observada nos animais que receberam dieta contendo óleo de soja e a dieta controle. Já a deposição de gordura corporal foi superior aos animais alimentados com a dieta controle. Uma maior deposição de nutrientes corporais é reflexo da eficiência de utilização dos nutrientes disponibilizados na dieta, sugerindo que a utilização de óleo de canola em dietas para piava otimiza seu metabolismo energético e proteico, refletindo em melhores índices produtivos.

O baixo ganho de peso observado no presente estudo, independente do tratamento, é considerado normal para espécies do gênero Leporinus na fase juvenil, visto que o crescimento lento é característico destes animais, parâmetro que já foi observado anteriormente em estudos desenvolvidos com este gênero por outros autores (VIEIRA et al. 2005, SIGNOR et al. 2007, PIANESSO et al. 2013).

A presença de cecos pilóricos no intestino das piavas pode ter contribuído para a obtenção dos presentes resultados, uma vez que possuem características histológicas e histoquímica semelhantes as do intestino adjacente (ROTTA 2003), servindo para aumentar a superfície de contato intestinal proporcionando maior aproveitamento dos alimentos, além de produzir um grande número de enzimas digestivas. $\mathrm{O}$ fato da dieta sem adição de óleo ter apresentado resultados inferiores somente em relação aos animais que receberam óleo de canola na dieta (Tabela 2) pode estar ligado a presença dessas estruturas, pois mesmo sendo uma dieta com menor percentual de lipídios, os cecos pilóricos compensariam com uma maior digestibilidade e aproveitamento do alimento, atendendo assim a demanda energética necessária para o crescimento.

Além disso, o fato das dietas experimentais serem isoproteicas aponta que esteja havendo catabolismo de proteína para suprir a demanda energética dos animais que receberam a dieta controle, compensando assim a menor quantidade de lipídios presente na dieta. Isso fica evidente ao relacionar a deposição de gordura e proteína corporal, que foi significativamente menor para os animais alimentados com esta dieta (Tabela 2). Observando a composição centesimal das dietas utilizadas nesse estudo (Tabela 1) nota-se que no tratamento controle há uma menor quantidade de lipídios, o que explicaria a baixa deposição de gordura corporal pelas piavas (Tabela 2).

A formulação de dietas sem a adição de lipídios não é recomendada para peixes, a menos que os demais ingredientes utilizados contribuam com quantidades mínimas desse nutriente, pois deficiências em AGE são responsáveis por grande parte das doenças nutricionais presentes na piscicultura comercial (SUTTON et al. 2006). Dentre os sinais de deficiências de AGE observa-se a redução do crescimento e apetite e aumento na conversão alimentar (BORBA et al. 2003). Além disso, na falta de lipídios os peixes vão utilizar a energia proveniente de proteínas e carboidratos e o excesso do último pode ocasionar acúmulo de glicogênio no músculo, diminuindo a qualidade da carne produzida (SANTOS \& OBA 2009).

Não foram observadas diferenças significativas entre os tratamentos testados para o FC e a TCE das piavas (Tabela 2), porém, os valores obtidos foram superiores aos relatados por RADÜNZ NETO et al. (2006), que obtiveram TCE de 1\%/dia e FC de 1,1 ao trabalhar com piavas recebendo dietas similares a deste estudo, testando diferentes fontes proteicas durante um período de 40 dias. O FC é um importante indicador do grau de higidez dos animais e seu valor reflete as condições nutricionais recentes e gastos das reservas em atividades cíclicas (GOMIERO et al. 2010). Assim, a ausência de diferença entre os tratamentos testados evidencia que as diferentes fontes lipídicas não influenciaram o estado fisiológico dos juvenis de piava utilizados no estudo. PIANESSO et al. (2013) ao testar substituição do farelo de soja por farelo de linhaça para piavas com peso inicial de $9,0 \pm 2,5 \mathrm{~g}$ durante 30 dias, também não encontraram diferença significativa para a variável acima citada.

Aglicose plasmática dos peixes está relacionada a respostas metabólicas dos animais em função de alterações nas dietas, também podendo servir como indicativo de saúde (KUMAR et al. 2010). No presente estudo não foram observadas diferenças significativas para esse parâmetro (Tabela 3). Sugerese que tais resultados relacionem-se ao fato das dietas experimentais conterem apenas ingredientes de origem vegetal em sua composição (Tabela 1), adicionados em quantidades muito semelhantes, os quais proporcionam níveis semelhantes de glicose 
Tabela 3 - Glicose e enzimas digestivas de juvenis de piava alimentadas com dietas contendo óleos vegetais. Table 3 - Glucose and juvenile digestive enzymes piava fed diets containing vegetable oils.

Fontes de lipídios

\begin{tabular}{lcccccc}
\hline Variáveis & Linhaça & Soja & Canola & Milho & Controle & P \\
\hline Glicose & $82,33 \pm 16,77$ & $81,00 \pm 15,00$ & $69,00 \pm 16,46$ & $80,67 \pm 14,97$ & $73,33 \pm 10,40$ & NS \\
Lipase & $0,45 \pm 0,04$ & $0,50 \pm 0,04$ & $0,46 \pm 0,13$ & $0,45 \pm 0,11$ & $0,41 \pm 0,16$ & NS \\
Tripsina & $7,26 \pm 0,77$ & $8,59 \pm 1,10$ & $7,21 \pm 0,66$ & $8,37 \pm 1,25$ & $8,96 \pm 0,63$ & NS \\
Quimotripsina & $33,07 \pm 2,74^{\mathrm{b}}$ & $46,211 \pm 5,25^{\text {a }}$ & $35,79 \pm 2,56^{\text {ab }}$ & $39,80 \pm 5,87^{\text {ab }}$ & $40,94 \pm 3,44^{\text {ab }}$ & $*$ \\
\hline
\end{tabular}

Glicose: ( $\mathrm{g} \mathrm{dL}^{-1}$ ); Lipase: (U/mg de proteína); Tripsina: ( $\mu \mathrm{mol} / \mathrm{tame} / \mathrm{min} / \mathrm{mg}$ proteína); Quimotripsina: (mmol/ btee/min/mg proteína). Valores apresentados como médias \pm desvio padrão. Valores acompanhados de letras diferentes, na mesma linha, são estatisticamente diferentes de acordo com o teste de Tukey $\left({ }^{*} \mathrm{p}<0,05 ;{ }^{*} \mathrm{p}<0,01\right)$.

plasmática por conta da quantidade de carboidratos presentes nos ingredientes (KUMAR et al. 2010).

A atividade das enzimas digestivas pode ser observada na Tabela 3 , onde observa-se que a atividade de lipase e tripsina não diferiram entre os tratamentos testados. Já a atividade da quimotripsina foi menor ( $p>0,05)$ nas piavas alimentadas com dieta contendo óleo de linhaça, quando comparada a atividade desta enzima nos animais que receberam óleo de soja (Tabela 3), indicando uma ação prejudicial do óleo de linhaça sobre a digestão proteica. Segundo LUNDSTEDT et al. (2004) o principal fator que promove alteração na produção de quimotripsina pelos peixes é o tipo de dieta fornecida para os animais, o que está relacionado aos ingredientes utilizados para sua formulação, incluindo a fonte lipídica.

O conhecimento da quantidade e especificidade de cada enzima é um instrumento importante para obter respostas sobre o processo digestivo do animal, a digestibilidade de alimentos e o hábito alimentar dos peixes. Entretanto, a fonte e quantidade de nutrientes podem alterar o perfil de enzimas produzidas e sua concentração no trato digestivo dos animais (LUNDSTEDT et al. 2004, STECH et al. 2009).

Uma variedade de lipídios de origem vegetal e animal, estão disponíveis para serem utilizados como ingredientes energéticos em dietas para peixes. Sabe-se que há reflexo da composição da dieta no perfil lipídico depositado por animais aquáticos (MAINA et al. 2003). Embora já tenham sido detectadas habilidades em alongar e dessaturar ácidos graxos, para espécies nativas como a piava, não há o conhecimento básico de qual fonte lipídica é melhor aproveitada por estes peixes e até mesmo informações sobre sua composição lipídica corporal, de seus ovos e larvas (GARCIA et al. 2012). Dessa maneira, este estudo colabora com uma necessidade do setor aquícola e possibilita nortear a escolha do óleo a ser incluído em dietas formuladas para a espécie.

Além dos parâmetros de qualidade nutricional e dos benefícios proporcionados ao crescimento, já discutidos neste trabalho, outro aspecto importante a ser considerado na escolha da fonte lipídica a ser empregada nas dietas é o custo do ingrediente. Tornase necessário, observar a disponibilidade do produto e preço na região, antes de optar pelo óleo que irá compor a dieta. Sendo assim, mais estudos necessitam ser realizados com peixes nativos do Brasil, bem como, outras fontes lipídicas alternativas, gerando dados sobre desempenho e nutrição que darão suporte para a fabricação de dietas com maior qualidade e específicas para cada espécie de peixe cultivada no nosso país.

\section{CONCLUSÃO}

O desempenho de juvenis de piava foi influenciado pela adição de óleos a dieta, sendo que entre as fontes lipídicas utilizadas, o óleo de canola otimizou o crescimento e deposição proteica dos peixes.

\section{REFERÊNCIAS}

AOAC - Association of Official Analytical Chemists. 1995. Official methods of analysis of the association of the official analysis chemists. 16.ed. Arlington: AOAC.

BENÍTEZ-DORTA V et al. 2013. Total substitution of fish oil by vegetable oils in senegalese sole (Solea senegalensis) diets: effects on fish performance, biochemical composition, and expression of some glucocorticoid receptor-related genes. Fish Physiology and Biochemiatry 39: 335-349.

BORGES P et al. 2014. Senegalese sole juveniles can cope with diets devoid of supplemental fish oil while preserving flesh nutritional value. Aquaculture 418/419: 116-125. 
BLIGH EG \& DYER WJ. 1959. A rapid method of total lipid extraction and purification. Canadian Journal of Biochemistry and Physiology 37: 911-917.

BORBA MR et al. 2003. Growth, lipogenesis and body composition of piracanjuba (Brycon orbignyanus) fingerlings fed different dietary protein and lipid concentrations. Aquatic Living Resources 16: 362-369.

GARCIA AS et al. 2012. Lípidios. In: FRACALOSSI DM \& CYRINO JEP. Nutriaqua - Nutrição e alimentação de espécies de interesse para aquicultura brasileira. Florianópolis: SBAB. p.79-99.

GAWLICKA A et al. 2000. Activity of digestive enzymes in yolk-sac larvae of Atlantic halibut (Hippoglossus hippoglossus): indication of readiness for first feeding. Aquaculture 184: 303-314.

GOMIERO LM et al. 2010. Relação peso-comprimento e fator de condição de Oligosarcus hepsetus (Cuvier, 1829) no Parque Estadual da Serra do Mar - Núcleo Santa Virgínia, Mata Atlântica, Estado de São Paulo, Brasil. Biota Neotropical 10: 101-105.

HUMMEL BCW. 1959. A modified spectrophotometric determination of chymotrypsin, trypsin and thrombin. Canadian Journal of Biochemistry and Physiology 37: 1393-1399.

KUMAR V et al. 2010. Physiological, haematological and histopathological responses in common carp (Cyprinus carpio L.) fingerlings fed with differently detoxified Jatropha curcas kernel meal. Food and Chemical Toxicology 48: 2063-2072.

LOSEKANN ME et al. 2008. Alimentação do jundiá com dietas contendo óleos de arroz, canola ou soja. Ciência Rural 38: 225-230.

LUNDSTEDT LM et al. 2004. Digestive enzymes and metabolic profile of Pseudoplatystoma corruscans (Teleostei: Siluriformes) in response to diet composition. Comparative Biochemistry and Physiology 137: 331-339.

MAINA JG et al. 2003. Partial replacement of fishmeal with sunflower cake and corn oil in diets for tilapia Oreochromis niloticus (Linn): effect on whole body fatty acids. Aquaculture Research 34: 601-608.

MPA - Ministério da Pesca e Aquicultura. 2014. $1^{\circ}$ Anuário Brasileiro da Pesca e Aquicultura. Brasil. Disponível em: <http://formsus.datasus.gov.br/ novoimgarq/16061/2489520_218117.pdf $>$. Acesso em: 24 mar. 2015.

MARTINO RC et al. 2002. Performance and fatty acid composition of surubim (Pseudoplatystoma corruscans) fed diets with animal and plant lipids. Aquaculture 209: 233-246.

MELO JFB et al. 2002. Desenvolvimento e composição corporal de alevinos de jundiá (Rhamdia quelen) alimentados com dietas contendo diferentes fontes de lipídios. Ciência Rural 32: 323-327.

NG WK et al. 2013. Effects of dietary fish and vegetable oils on the growth, tissue fatty acid composition, oxidative stability and vitamin E content of red hybrid tilapia and efficacy of using fish oil finishing diets. Aquaculture 372: 97-110.

PEREIRA MC et al. 2011. Óleos vegetais em rações para o híbrido tambacu (macho Piaractus mesopotamicus $\mathrm{x}$ fêmea Colossoma macropomum). Revista Brasileira de Saúde e Produção Animal 12: 551-562.

PIANESSO D et al. 2013. Substituição do farelo de soja pelo farelo de linhaça em dietas para a piava (Leporinus obtusidens). Semina. Ciências Agrárias 34: 419-430.

RADÜNZ NETO J et al. 2006. Alimentação da piava (Leporinus obtusidens) com diferentes fontes protéicas. Ciência Rural 36: 1611-1616.

ROSTAGNO HS. 2011. Tabela Brasileira para aves e suínos. Composição de Alimentos e Exigências Nutricionais. 3.ed. 2011. Disponível em: <http://www.lisina.com.br/arquivos/ Geral\%20Portugu\%C3\%AAs.pdf $>$. Acesso em: 15 abr. 2015.

ROTTA MA. 2003. Aspectos gerais da fisiologia e estrutura o sistema digestivo dos peixes relacionados à piscicultura. Corumbá: Embrapa. 49p.

SANTOS B \& OBAET. 2009. Dieta: ferramenta importante para manejo dos peixes no cultivo. In: TAVARES-DIAS M. (Org.) Manejo e sanidade de peixes em cultivo. Macapá: Embrapa. p.89-105.

SIGNOR AA et al. 2007. Farinha de vísceras de aves na alimentação de alevinos de piavuçu (Leporinus macrocephalus). Ciência Rural 37: 828-834.

SIGNOR AA et al. 2010. Proteína e energia na alimentação de pacus criados em tanques-rede. Revista Brasileira de Zootecnia 39: 2336-2341.

STECH MR et al. 2009. Fatores que afetam a produção de enzimas digestivas em peixes e o uso de enzimas exógenas como ferramentas em nutrição de peixes. Ensaios e Ciências 13: 79-93.

SUTTON J et al. 2006. Impact of iron-catalyzed dietary lipid peroxidation on growth performance, general health and flesh proximate and fatty acid composition of Atlantic salmon (Salmo salar L.) reared in seawater. Aquaculture 257: 534-557.

TAITSON PF et al. 2008. Gene banking of the neotropical fish Leporinus obtusidens (Valenciennes, 1836): A protocol to freeze its sperm in the field. Animal Reproduction Science 105: 283-291.

VARGAS RJ et al. 2007. Desempenho de alevinos de tilápia do Nilo (Oreochromis niloticus) alimentados com dietas contendo diferentes fontes de lipídios. Revista Brasileira de Agrociências 13: 377-381.

VIEIRA JS et al. 2005. Efeito do processamento do milho sobre o desempenho e composição de carcaça de piaba (Leporinus friderici) criada em tanques-rede. Ciência e Agrotecnologia 29: 453-458. 